\title{
Wind Energy Potential at Badin and Pasni Costal Line of Pakistan
}

\author{
Ghulam Sarwar Kaloi ${ }^{*}$, Jie Wanga, Mazhar Hussain Balocha ${ }^{a^{*}}$ and Sohaib \\ Tahira
}

${ }^{a}$ School of Electronic information and Electrical Engineering, Shanghai Jiao Tong University, China

$a^{*}$ Department of Electrical Engineering, MUET, SZAB Khairpur Mir's Campus, Sindh, Pakistan

\begin{abstract}
Unfortunately, Pakistan is facing an acute energy crisis since the past decade due to the increasing population growth and is heavily dependent on imports of fossil fuels. The shortage of the electricity is 14-18 hours in rural areas and 8-10 hours in urban areas. This situation has been significantly affecting the residential, industrial and commercial sectors in the country. At this time, it is immense challenges for the government to keep the power supply provision continue in the future for the country. In this situation, it has been the increased research to explore renewable energy resources in the country to fulfill the deficit scenario in the state. The renewable energy sector has not penetrated in the energy mix, currently in the upcoming markets. This paper highlights the steps taken by the country in the past and is taking steps at the present time to get rid of from the existing energy crisis when most urban areas are suffering from power outages for 12 hours on regular basis. Until 2009, no single grid interconnected wind established, but now the circumstances are changing significantly and wind farms are contributing to the national grid is the reality now. The initiation of the three wind farms interconnection network and many others in the pipeline are going to be operational soon. The federal policy on wind energy system has recently changed. Surprisingly, the continuing schemes of the wind farm are getting slow. This paper reviews developments in the wind energy sector in the country and lists some suggestions that can contribute to improving the penetration of wind energy in the national energy sector.
\end{abstract}

Keywords: Wind energy, evolution of wind resource, Wind sites of Pakistan

Article History: Received Dec $16^{\text {th }}$ 2016; Received in revised form May 15th 2017; Accepted June 18 th $^{\text {th }}$ 2017; Available online

How to Cite This Article: Kaloi,G.S., Wang, J., Baloch, M.H and Tahir, S. (2017) Wind Energy Potential at Badin and Pasni Costal Line Pakistan. Int. Journal of Renewable Energy Development, 6(2), 103-110.

https://doi.org/10.14710/ijred.6.2.103-110

\section{Introduction}

Pakistan is a rich country with every form of energy resources, effective use of these resources can boost the economy of the country. The energy sector in Pakistan is directly depending on the government and private organizations. The energy sector in Pakistan is basically under the direct or the indirect control of the government departments or private organizations. The energy sector infrastructure is currently under development in Pakistan. Industrial, domestic, transport, agriculture and commercial sectors are major sectors of energy consumption in Pakistan. Commercial consumption has decreased at the lowest rate of approximately $2.8 \%$, followed by domestic, transportation and industrial consumption rose by $9 \%, 4.6 \%$ and $3.8 \%$, respectively. The energy consumption in agriculture and other government sectors has decreased significantly by massive energy consumption.

Nuclear, hydel, coal, wind, LPG, gas and oil are prime resources in Pakistan. Since the per capita consumption of electricity and power outages are constantly increasing in Pakistan, it has become the national cause for public to take measures and policies to develop infrastructure for power generation including the increasing demand for constant energy supply. It has become a national public cause for power generation infrastructure, measures and policies to increase demand for energy (Goswami and Kreith 2015).

The installed power capacity of Pakistan is $22000 \mathrm{MW}$. The growing demand for the electricity is $17000 \mathrm{MW}$. The shortfall is $5000-6000 \mathrm{MW}$. The power requirement in 2030 will be more than $14000 \mathrm{MW}$. In 2014 and 2015, the energy consumption in Pakistan

\footnotetext{
* Corresponding Author: +86-15821917001(Phone)

Email: sarwar.kaloi59@gmail.com
} 
was 26.27 million tons of oil (TOE) that was $0.12 \%$ less than the previous years. In the same year supply of the energy has increased by 4.9 percent to 44.6 million TOE (Patel 2005).

Various energy sub-sectors are increasing due to the energy consumption of natural gas by 7 percent, oil 3.7 percent and declined by 8.9 percent. From 1990 and 2005, Pakistan had abundant electricity. But the golden period could not remain longer and nowadays countering a big challenge to reduce the shortfall of the electricity. Power crisis started in 2006 to onward and day by day demand kept increasing. But in the current situation, this gap has increased when the power shortfall surged about 5500MW.Once again in the month of June 2015, this shortfall crossed over 6000 MW. To reduce the demand and power supply gap, the menace of load shedding started ranging from 8 to 10 hours power outages in urban and 18 to 20 hours in rural areas. (Boyd 2003)-(Bhutto and Karim 2007). It has been predicted that owing to the increasing awareness about the benefits of the wind and solar energy production of cheap forms of energy for the largest energy markets in Asia within 10 years(Siddique and Wazir 2016). Optimistic estimations also estimate that by 2030, one fifth of the electricity demands of the planet will be met by wind energy. This indicates not only environmental but economic benefits for all countries to include wind power as clean and renewable source of energy. This paper attempts to highlight the efforts done in research and developments of wind energy sector in Pakistan (Fettweis and Zimmermann 2008). A few years ago, economic growth had been held back by the energy sector. Since 2013, the rapid growth in energy demand has led to more concentration and focus on the energy sector (especially electricity). Now a day's situation is worsening and power crisis is affecting everyone. This issue should be resolved on an immediate basis. No doubt growth of GDP and consumption rate of the energy is extremely interconnected as shown in Fig.3. It can be observed that energy consumption has increased and also growth rate has increased (Hasan, Subhani et al. 2012). The energy crisis is the most important issue in Pakistan. According to some estimates, the energy shortages have cost up to 4 percent GDP loss in Pakistan. In the last few years, a lot of industries and factories have shut down due to the prevailing energy crisis. The energy crisis is the biggest issue for the economy of Pakistan. Five years ago power crisis was originated when power production depended on the imported furnace oil and lack of the hydropower generation due to the water crisis in Pakistan. It has been the increased cost of power generation due to line losses that has increased the tariffs rates that affected the direct power generation, transmission, and distribution companies. Also, Pakistan energy statistics from 2012 estimate that an annual electricity consumption of a meager 74 billion $\mathrm{kW} \mathrm{h}$ consumption per capita is $456.64 \mathrm{~kW} \mathrm{~h}$, one of the lowest in the world (Alam 2013, sarwar Kaloi, Wang et al. 2016). Still, Pakistan has been unsuccessful in fulfilling its energy demand by conventional fuels and remains among the ten most energy deficient countries in the world. The current distribution system is not capable of supplying more than $15,000 \mathrm{MW}$. In effect, the constricting bottleneck currently is distribution and not the generation as shown in Fig.1. Therefore, even if existing generating units are geared up to operate three-fourth of their capacity. The country simply does not have the infrastructure to distribute this power to users (Pakistan 2013). Hence, the total installed capacity in Pakistan is greater than the actual generated power while the actual generated power is less than the demand (Blackman and Wu 1999).

\section{Wind Energy Scenario in Pakistan}

Wind power technology in Pakistan's energy market started its course of action at a slow pace. It has developed the first known windmills used to pump ground water and grind grain in Iran about 500-900 AD being a direct neighbor of Iran, it is surprising, and however, the ancient history of Pakistan is silent about the existence of wind energy technology. It was not released until recently mountainous windy areas and the $1080 \mathrm{~km}$ long border with the Arabian Sea can be utilized for the installation of wind farms. It is reported that the main efforts were done to identify ways to take advantage of wind power in the 1980s. In the $1990 \mathrm{~s}$, there were installed two units of $10 \mathrm{kWh}$ and $1 \mathrm{kWh}$ in Sindh and Balochistan respectively(Mirza, Ahmad et al. 2009). It submitted a report on mapping the wind resources of the PCAT in March 2001, based on data contributed by the Pakistan Meteorological Department, which has been collecting for more than 50 years. This report was based on the data recorded at 50 stations in the country at the height of $2.10 \mathrm{~m}$. It has been getting the expected wind speed of $30 \mathrm{~m}$ high and has the potential for wind energy. In another report, the inclusion of parts of Sindh i.e. Chor, Badin, Hyderabad and Karachi because these were the best locations for wind energy exploitation. Also in 2001, the project started by the Ministry of Environment, with the support of Global Environment Facility (GEF) Trust Fund for the North and the United Nations. Development Programme under the name of "marketing potential of wind energy in Pakistan." This project is designed to determine the feasibility of a wind energy project in Pasni along with Makran coast of Balochistan. Unfortunately, this project failed due to the lack of wind data and incentives. However, given the value of recommendations on tariffs, and the policy framework and legal aspects that will pave the way for wind projects in the future (Sheikh 2010, Menges and Pfaffenberger 2015). In 2002, Pakistan 
purchased 14 small wind turbine generators (WTGs) from China, set up by the Pakistan Council of Renewable Energy Technologies (PCRET) for exhibition intentions. Among them, it was fixed that 8 WTGs in the coastal areas of Balochistan and six WTGs will be installed in the coastal sites of Sindh. It is considered that small wind turbines are in the process of rural electrification in the coastal areas of Sindh. (Kaloi et al. 2016, Sahir and Qureshi 2008).

By 2004, the foreign company finished the wind-diesel hybrid scheme effectively for rural electrification in a village of Sibi, Balochistan. In a study performed during 2004-2007, it has been measuring wind data at 20 locations from coastal areas of Sindh. According to international standards, Indus sites, Jamshoro, Nooriabad, Talhar and Keti Bunder, are excellent locations. In addition, Thana bowl Khan, Hyderabad, Gharo, and Thatta are examined to be good locations for wind power generation.

In 2011, Government of Pakistan passed the Alternative Energy Development Board Act (AEDB), in which, the Government of Pakistan has gone through alternative energy development Council Act, which empowers the AEDB to develop plans and policies for the use of renewable energy in the country, and the evaluation and adoption of renewable energy projects. Sindh government also directed the AEDB to be used as a middle during the interaction and coordination of national and international bodies for renewable energy technologies (Mohammadi et al. 2016). The previous policy was superseded in 2006 by the alternative and renewable energy policies of 2011. The provisions of this law suggest that Pakistan has an estimated wind power potential of $346 \mathrm{GW}$ of which about 60-70 GW technically is exploitable. The aim of government was to direct AEDB for minimum contribution of five percent in the national energy by wind and solar energy resources by 2030 .

In contrast, China has a well-established growing industry. It is a country with a population of 1.3 billion people, which becomes statistically $19.24 \%$ of the total world population, according to the statistics of China stands on top of the population of the world (Kaloi et al. 2016, Baloch et al. 2017). In 2010, China became the largest power generator in the world with a production of $4716 \mathrm{TWh}$, surpassed the United States of America, which produced the 4208 TWh. According to the Energy Information Administration (EIA), total energy production in China reached nearly $5126 \mathrm{TWh}$ in 2013. China is reliable in upholding the financial system and fast growth of GDP 7\% or more since the years leading up to China. China is second-largest oil consumer in the world and 10.7 million barrels consumption per annum. China is an advanced country compared to Pakistan and India, which are in the development stages yet. The exploitation of energy resources is vital for the economic growth of the country and the improvement of RES can contribute to the GDP growth in the perspective of ecological anxiety.

\section{Global Wind Energy Scenario}

In this context, review of a summary of developments in the field of wind energy play a vital role at the global level, with a particular focus on key areas of the realities of the global market, and the issues of technology, economics, and environmental performance: the prospects for wind energy and $R$ \& D. Exhibition highlights some insight for each of the fields now, with special attention to achieve the European market. More specifically, in the section of the facts in the global market ", it is presented that evolution of global wind power generation along with the leading market today, the European Union, the world's most important wind energy fact(Baloch, Kaloi et al. 2016, Kaloi, Wang et al. 2016). Following, in this section are a lot of technology issues and also discussions on the machines' upscale and up gradation to commence major technological characteristics of WTs. Issues such as integration of grid, the efficiency of the plant and the expansion of the small machines.

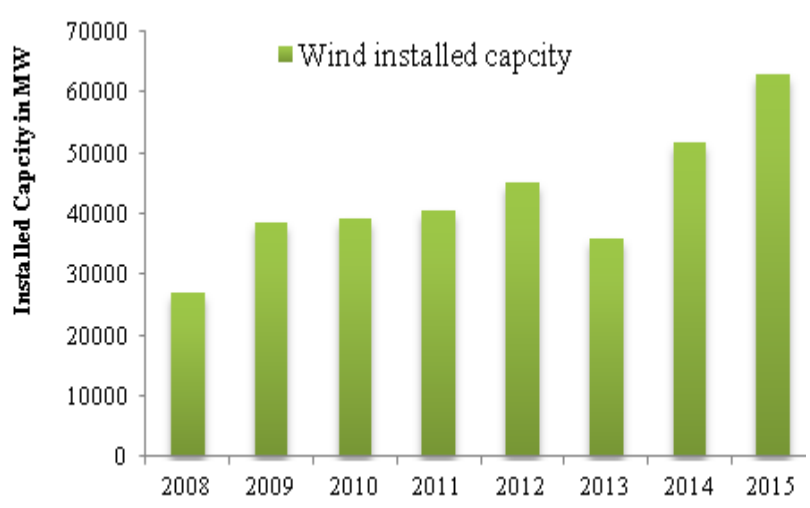

Fig.1. Wind power Installed capacity in World

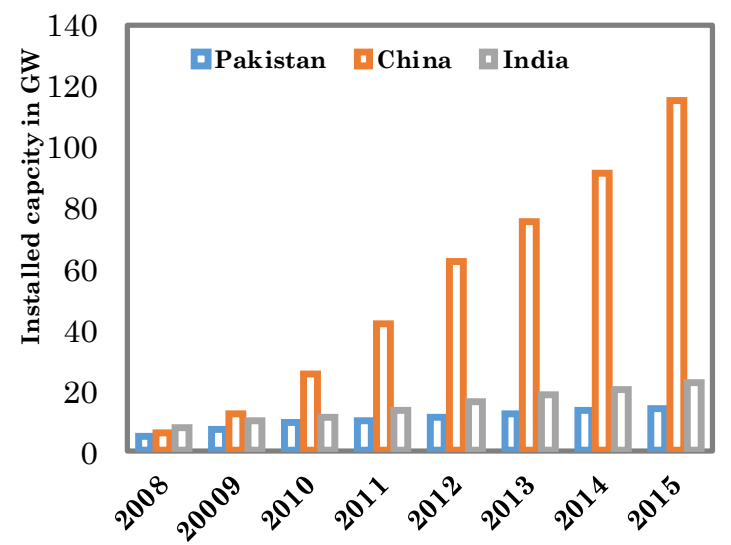

Fig.2. Installed capacity in Pakistan India and China 


\section{Wind potential evaluation of Badin and Pasni}

In literature, there are many ways to find out the wind speed data are summarized below, including averages and various frequency histograms. The data is distributed by the frequency distribution. Wind speed variations are deemed to be the most suitable for Rayleigh and Weibull distribution. It is calculated by wind speed variation diurnal, monthly, and yearly. The potential of wind energy for the site depends on the wind speed and the proportion of time that these speeds are available. In addition, the air density and turbines tower height, the turbines design affect electricity production, and all these aspects are considered in the following sections

\subsection{Characterization of Wind speed}

Wind speed variation with the height is given by the log law:

$$
\frac{u(Z)}{u_{r}}=\frac{\ln \left(Z / Z_{o}\right)}{\ln \left(Z_{r} / Z_{o}\right)}
$$

Where, $u(Z)$ is the wind speed height $Z$, reference wind speed $u_{r}$ at the height of reference $Z_{r}$, the surface roughness length $Z_{0}$, which describes the terrain roughness. Surface roughness values' length for different types of terrain is given in the literature. In this research, the surface roughness length $Z_{0}$ is analyzed from (1) using the measured speed at $10 \mathrm{~m}$ and 50 height (1) was used to analyze the speed of the wind at the height of $50 \mathrm{~m}$, since the wind turbine hub height is $50 \mathrm{~m}$ or more.

The function of Weibull probability density, which has normally utilized to illustrate the speed of wind distribution, is specified by:

$$
p(u)=\left(\frac{k}{C}\right)\left(\frac{u}{C}\right)^{k-1} \exp \left[-\left(\frac{u}{C}\right)^{k}\right]
$$

Where, scale factor $\mathrm{C}$, and shape factor $\mathrm{k}$. higher values of $\mathrm{k}$ show the sharper peaked curve $\mathrm{k}$ means smoother or more evenly distributed speeds. A value of $\mathrm{k}=2$ reduces the Weibull distribution and Rayleigh distribution, another function used for wind speed. To fit the measured data of Weibull distribution, a lot of techniques are described in the literature. To analyze Weibull parameters by using the speed data maximum. In like hood method following equations are used.

$$
\begin{aligned}
& k=\frac{1}{\left(\frac{\sum_{J=1}^{n} u_{J}^{k} \ln \left(u_{J}\right)}{\sum_{J=1}^{n} u_{J}^{k}}-\frac{\sum_{J=1}^{n} \ln \left(u_{J}\right)}{n}\right)} \\
& C=\frac{1}{\left(\frac{1}{n} \sum_{J=1}^{n} u_{J}^{k}\right)^{-\frac{1}{k}}}
\end{aligned}
$$

Where $u_{J}$ is wind speed, $n$ is wind speed data Eq: (3) starting point is responsible for $\mathrm{k}=2$ and $\mathrm{Eq}$ (4) only solution for $\mathrm{C}$.

Wind speeds at different heights superposed on the frequency distributions and Weibull distributions are depicted in Fig. 3 \& Fig 5. Notice that frequency distribution is exposed in percent at the same time as given by the probability of occurrence of wind speeds for Weibull distributions. The responsibility of Weibull distribution is a good and fit for data of wind speed accumulated from Badin and Pasni. Different heights are given in Table 1, the Weibull parameters, wind speed, and the available average wind power density. Split classification of wind speed for each month has carried out as depicted in Tabel1 and Table 2. The power density and average speed of monthly are presented in Fig. 4 and Fig (6), respectively. Wind speed is more in the summer season (AprilSeptember) but production of power generation done for the year, in the period of (November -January) is not included.
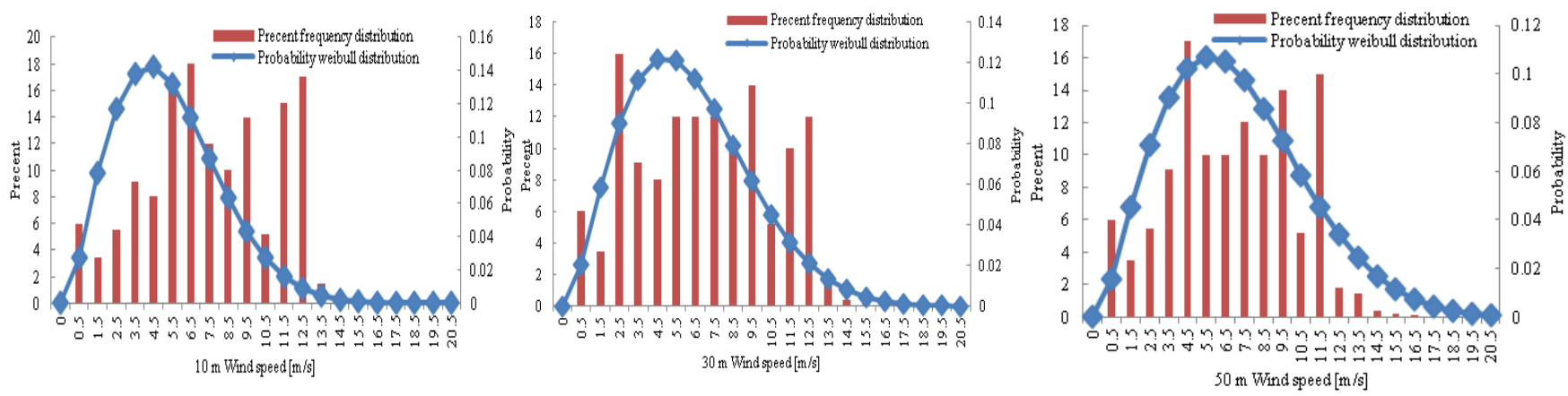

Fig.3. Weibull distribution of wind speeds for different heights at Badin over the years 
Table1.

Characterization of wind speed at Pasni by month

\begin{tabular}{|c|c|c|c|c|c|c|c|c|c|c|c|c|}
\hline & Jan & Feb & March & April & May & June & July & Aug & Sep & Oct & Nov & Dec \\
\hline \multicolumn{13}{|c|}{$10 \mathrm{~m}$ height } \\
\hline $\mathrm{U}_{\mathrm{avg}}$ & 2.88 & 3.26 & 3.48 & 5.3 & 7.59 & 6.45 & 8.62 & 5.76 & 5.66 & 2.7 & 2.07 & 2.8 \\
\hline St Dev & 2.2 & 2.4 & 2.4 & 2.4 & 2.6 & 3.1 & 3.3 & 2.2 & 2.1 & 2.4 & 1.6 & 2.3 \\
\hline $\mathrm{C}(\mathrm{m} / \mathrm{s})$ & 3.3 & 3.6 & 3.5 & 6.1 & 7.8 & 7.9 & 8.2 & 7.2 & 5.7 & 3.1 & 2.2 & 3.3 \\
\hline $\mathrm{k}$ & 1.3 & 1.5 & 1.4 & 1.9 & 2.4 & 2.2 & 2.5 & 2.6 & 2.5 & 1.3 & 1.3 & 1.3 \\
\hline $\mathrm{P} / \mathrm{A}\left(\mathrm{w} / \mathrm{m}^{2}\right)$ & 49 & 97 & 66 & 143 & 264 & 229 & 458 & 150 & 142 & 33 & 29 & 54 \\
\hline \multicolumn{13}{|c|}{$30 \mathrm{~m}$ height } \\
\hline $\mathrm{U}_{\text {avg }}$ & 4.02 & 4.9 & 5.05 & 7.31 & 9.52 & 8.09 & 10.41 & 6.93 & 7.05 & 4.27 & 3.56 & 4.03 \\
\hline St Dev & 2.5 & 2.6 & 2.3 & 2.6 & 3.2 & 3.3 & 4.1 & 2.7 & 2.4 & 2.7 & 1.8 & 2.5 \\
\hline $\mathrm{C}(\mathrm{m} / \mathrm{s})$ & 4.7 & 5.3 & 5.8 & 8.2 & 9.4 & 9.4 & 10.1 & 8.9 & 7.2 & 4.7 & 4 & 4.8 \\
\hline $\mathrm{k}$ & 1.51 & 1.47 & 2.23 & 3.53 & 3.69 & 3.26 & 4.07 & 3.98 & 4.08 & 2.41 & 1.66 & 1.54 \\
\hline $\mathrm{P} / \mathrm{A}\left(\mathrm{w} / \mathrm{m}^{2}\right)$ & 107 & 201 & 136 & 331 & 671 & 436 & 847 & 252 & 263 & 77 & 65 & 104 \\
\hline \multicolumn{13}{|c|}{$50 \mathrm{~m}$ height } \\
\hline $\mathrm{U}_{\text {avg }}$ & 4.8 & 5.77 & 5.96 & 8.46 & 10.58 & 9.03 & 11.3 & 7.68 & 7.91 & 5.21 & 4.41 & 4.82 \\
\hline St Dev & 3 & 3 & 2.7 & 2.7 & 3.4 & 3.6 & 4.3 & 3 & 2.6 & 3 & 2.4 & 2.9 \\
\hline $\mathrm{C}(\mathrm{m} / \mathrm{s})$ & 5.6 & 6.3 & 7 & 9.4 & 10.5 & 10.4 & 11.9 & 9.9 & 8.2 & 5.7 & 5 & 5.7 \\
\hline $\mathrm{k}$ & 1.51 & 1.62 & 2.35 & 3.84 & 3.88 & 3.37 & 4.06 & 3.99 & 4.14 & 2.44 & 1.66 & 1.56 \\
\hline $\mathrm{P} / \mathrm{A}\left(\mathrm{w} / \mathrm{m}^{2}\right)$ & 183 & 288 & 214 & 246 & 905 & 597 & 1085 & 342 & 370 & 139 & 125 & 176 \\
\hline
\end{tabular}
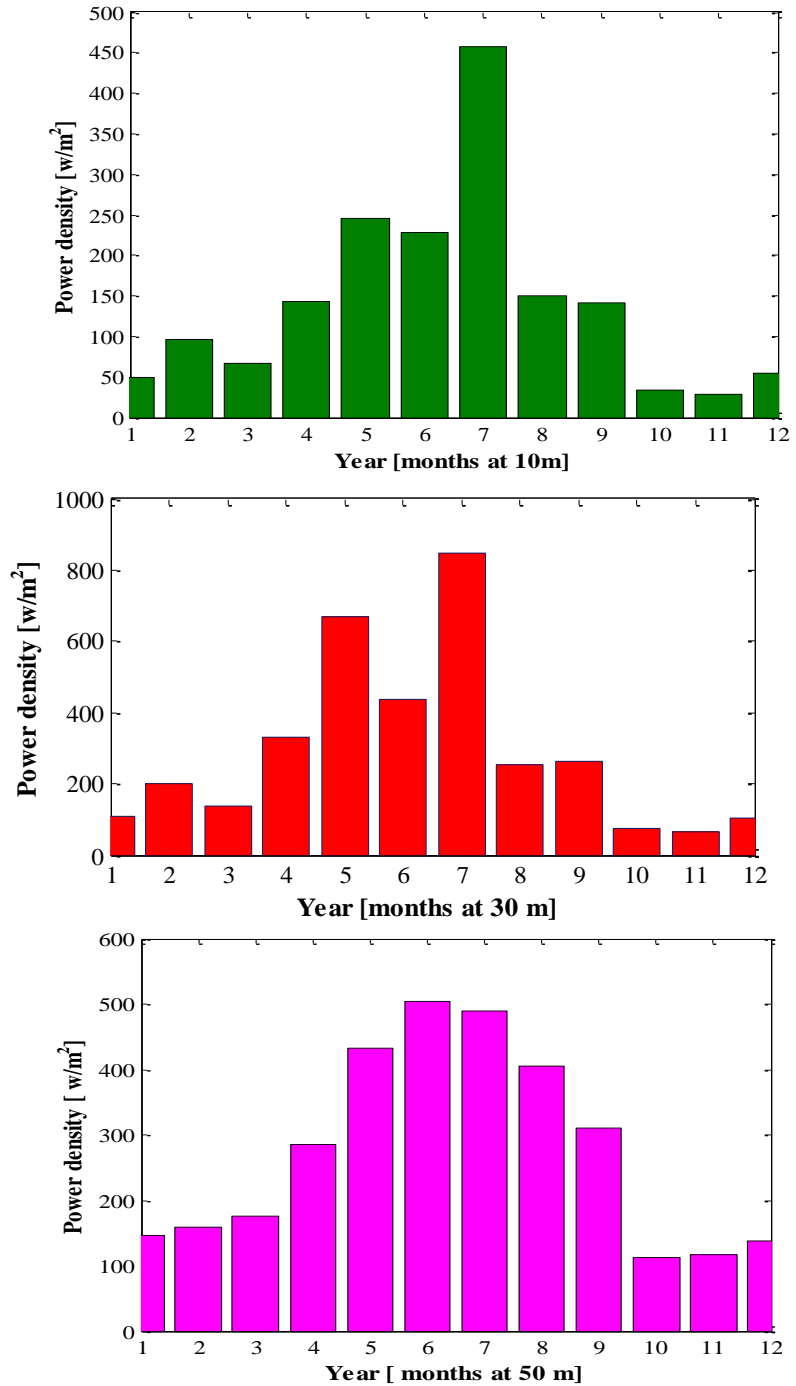

Fig.4. Power density for different heights at Badin over the year

\subsection{Wind power characterization}

The availability of the average power in a unit area depicts the average power density of that particular area in the turbine rotor and it can be premeditated as:

$$
\frac{P}{A}=0.5 \rho \frac{1}{n} \sum_{J=1}^{n} u_{J}^{3}
$$

The average power density all over the year is calculated almost $414 \mathrm{~W} / \mathrm{m} 2$ at $50 \mathrm{~m}$ height in Badin and Pasni, interpreting the energy density for the rotor area equals to $3267 \mathrm{kWh} / \mathrm{m} 2$ in a year. A particular turbine produces an actual power that is dependent upon the height of the hub, capacity factor (efficiency) of the turbine and the rotor area of the turbine. The power curve of the turbine (depicted by the relation of the turbine power output $P \mathrm{~W}(U)$ and the wind speed) and the wind speeds, if given, makes the average power of the wind turbine achievable by the relation:

$$
P w=\frac{1}{n} \sum_{J=1}^{n} P w\left(u_{J}\right)
$$

Furthermore, the total output power is acquired by multiplying the quantity of time intervals (i.e., hours). By making the use of binned wind velocity information, the power generated will also be calculated by the relation:

$$
P w=\frac{1}{n} \sum_{J=1}^{n_{B}} P w\left(m_{J}\right) N_{J}
$$

Where the $\mathrm{N}_{J}$ is a number of cycles within the jth bin, the midpoint of which is $m_{J}$ and $n_{B}$ is the totality of boxes. 
Citation: Kaloi,G.S., Wang, J., Baloch,M.H. and Tahir, S. (2017) Wind Energy Potential at Badin and Pasni Costal Line Pakistan.. International Journal of Renewable Energy Development, 6(2), 103-110,https://doi.org/10.14710/ijred.6.2.103-110

$\mathrm{P}$ a g e | 108

Table 2.

Characterization of wind speeds at Badin by month

\begin{tabular}{|c|c|c|c|c|c|c|c|c|c|c|c|c|}
\hline & Jan & Feb & March & April & May & June & July & Aug & Sept & Oct & Nov & Dec \\
\hline \multicolumn{13}{|l|}{$10 \mathrm{~m}$ height } \\
\hline $\mathrm{U}_{\text {avg }}$ & 2.23 & 2.15 & 3.12 & 1.98 & 1.89 & 1.31 & 1.21 & 1.851 & 2.123 & 3.461 & 3.861 & 3.212 \\
\hline St Dev & 3.1 & 2.81 & 2.82 & 3.3 & 3.2 & 3.5 & 3.3 & 3.8 & 2.91 & 2.5 & 2.4 & 2.8 \\
\hline $\mathrm{C}(\mathrm{m} / \mathrm{s})$ & 3.4 & 3.1 & 3.2 & 4.5 & 5.8 & 6.2 & 6 & 5.2 & 3.6 & 2.2 & 2.2 & 3.1 \\
\hline $\mathrm{K}$ & 1.1 & 1.2 & 1.21 & 1.3 & 1.7 & 1.81 & 1.75 & 1.3 & 1.2 & 1.1 & 1.2 & 1.3 \\
\hline $\mathrm{P} / \mathrm{A}\left(\mathrm{w} / \mathrm{m}^{2}\right)$ & 154.1 & 115.1 & 160.1 & 187 & 240 & 211 & 256.1 & 156.1 & 157.2 & 104.2 & 48.1 & 102.1 \\
\hline \multicolumn{13}{|l|}{$30 \mathrm{~m}$ height } \\
\hline $\mathrm{U}_{\text {avg }}$ & 4.394 & 4.925 & 6.08 & 3.63 & 2.654 & 1.168 & 1.396 & 2.955 & 4.167 & 6.546 & 7.371 & 5.538 \\
\hline St Dev & 2.41 & 2.42 & 2.9 & 3.1 & 3 & 3.3 & 3.2 & 3 & 2.7 & 2.4 & 2.5 & 2.6 \\
\hline $\mathrm{C}(\mathrm{m} / \mathrm{s})$ & 4.5 & 4.7 & 4.3 & 5.8 & 7.5 & 8 & 7.8 & 7.3 & 6 & 3.7 & 3.9 & 4.5 \\
\hline $\mathrm{K}$ & 1.81 & 1.82 & 1.41 & 1.83 & 2.5 & 2.45 & 2.53 & 2.55 & 2.1 & 1.7 & 1.8 & 1.9 \\
\hline $\mathrm{P} / \mathrm{A}\left(\mathrm{w} / \mathrm{m}^{2}\right)$ & 89.3 & 92.1 & 116.1 & 185 & 292 & 353 & 330 & 267.2 & 160.1 & 65.1 & 67.1 & 85.1 \\
\hline \multicolumn{13}{|l|}{$50 \mathrm{~m}$ height } \\
\hline $\mathrm{U}_{\text {avg }}$ & 5.321 & 5.412 & 7.23 & 4.32 & 3.62 & 2.12 & 2.31 & 2.562 & 5.212 & 6.892 & 8.124 & 6.232 \\
\hline St Dev & 3 & 3.1 & 2.7 & 3 & 3.2 & 3.8 & 3.6 & 3 & 3.1 & 2.9 & 2.8 & 2.9 \\
\hline $\mathrm{C}(\mathrm{m} / \mathrm{s})$ & 5 & 5.6 & 5 & 6.7 & 8.6 & 9.1 & 8.9 & 8.5 & 7.4 & 4.5 & 4.7 & 5.4 \\
\hline $\mathrm{K}$ & 1.65 & 1.81 & 1.51 & 1.8 & 2.52 & 2.6 & 2.5 & 2.7 & 2.2 & 1.56 & 1.67 & 1.85 \\
\hline $\mathrm{P} / \mathrm{A}\left(\mathrm{w} / \mathrm{m}^{2}\right)$ & 145.3 & 158.1 & 176.4 & 284 & 432 & 503 & 490. & 404.4 & 309.8 & 113.1 & 117.6 & 138.5 \\
\hline
\end{tabular}

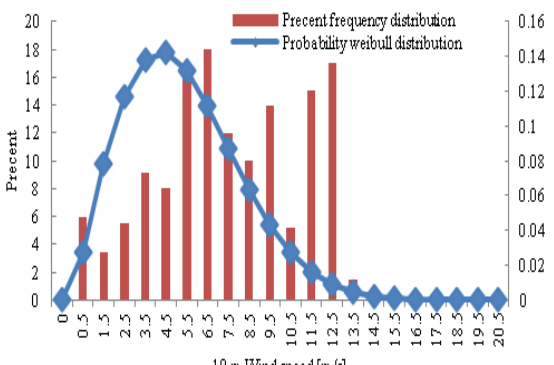

$10 \mathrm{~m}$ Wind speed $[\mathrm{m} / \mathrm{s}]$

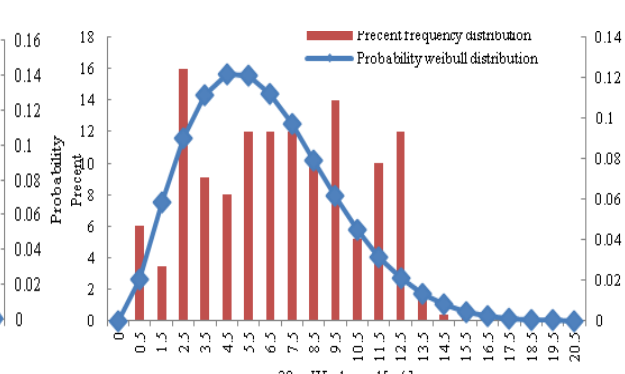

$30 \mathrm{~m}$ Wind speed $[\mathrm{m} / \mathrm{s}]$

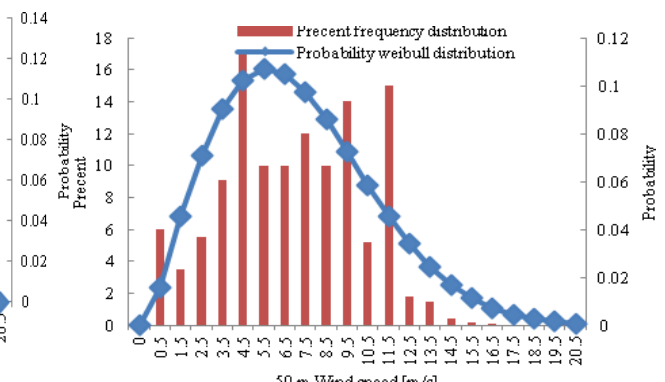

$0 \mathrm{~m}$ Wind speed $[\mathrm{m} / \mathrm{s}$

Fig.5. Weibull distribution of wind speeds for different heights at Badin over the years

\section{Results \& Discussion}

American wind power chart manuscript characterized seven wind energy sources in order to depict the wind power as a valuable asset at a site, beginning from sort 1 (slightest vitality) to arrangement 7 (most vitality). The average power density of almost $414 \mathrm{~W} / \mathrm{m}^{2}$ at the height of $50 \mathrm{~m}$ along with the average wind speed of $7.16 \mathrm{~m} / \mathrm{s}$ per annum, categorize the Badin and Pasni in class 4, which is the most appropriate class for the wind turbine applications varying from stand alone and small turbines to the huge wind farms and larger turbine units. Moreover, the larger wind farm requires a comprehensive analysis of the expenditures and the advantages, which are not lying in the scope of this paper, whereas an assessment of a stand-alone unit for a local community is shown underneath.

There are numerous advantages of a mini-grid or small off grid power system based on the renewable energy. It is observed in several cases that the main grid is not extendable to the small or remote communities or far away areas. Yet, apart from the availability of electricity in the grid, it is cheaper to only use it as a backup i.e. for the low wind season. At Badin and Pasni, the speed of wind is relatively much higher in the months of summer, when there is a huge demand for electricity in that period. By selling the extra electricity to the grid, it becomes much suitable to earn a good profit.

Expecting that the 29000 people living in Badin use power at the national expense of $424 \mathrm{kWh}$ every year, the overall necessity to consume energy is 1230 MWh. Moreover, by choosing the $150 \mathrm{~kW}$ $\mathrm{N} 27 / 150$ turbine, having the diameter of $27 \mathrm{~m}$. It should be mounted at a center top of $30 \mathrm{~m}$, rather than the height of $50 \mathrm{~m}$, decided for evaluation and comparison purposes, as shown in Table 4. Making utilization of $30 \mathrm{~m}$ stature wind speeds, the output energy of turbine is computed as $475 \mathrm{MWh}$ per annum. Let's suppose that such three turbines have been installed as depicted in Table 3. 

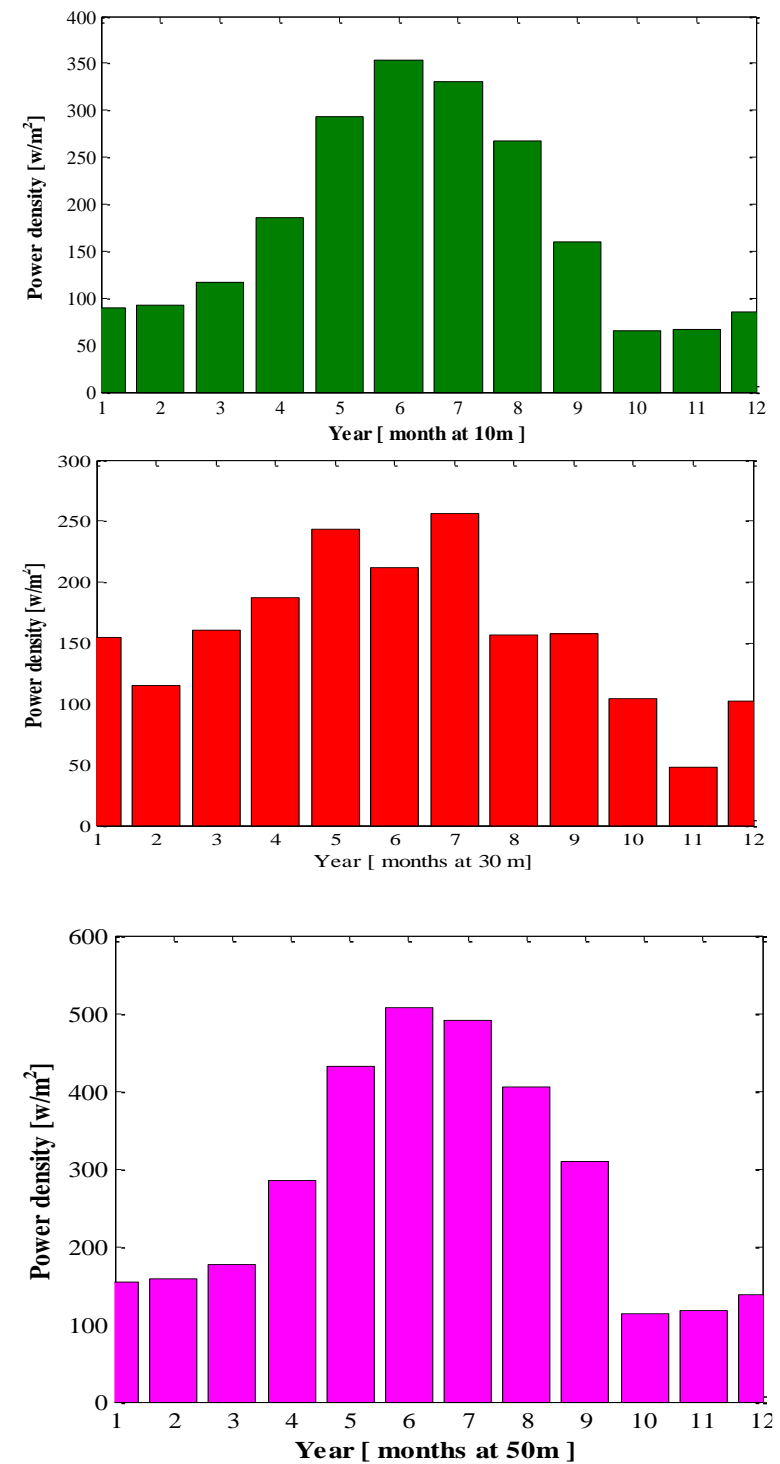

Fig.6. Power density for different heights at Badin over the year

Table 3.

Selected Parameters of Nordex Wind Turbine

\begin{tabular}{ccccccc}
\hline $\begin{array}{c}\text { Turbine } \\
\text { Model }\end{array}$ & $\begin{array}{c}\text { Rated Power } \\
(\mathbf{k w})\end{array}$ & $\begin{array}{c}\text { Rotor } \\
\text { Diameter }(\mathbf{m})\end{array}$ & $\begin{array}{c}\text { Hub Height } \\
\mathbf{( m )}\end{array}$ & $\begin{array}{c}\text { Cut in Wind } \\
\text { speed }(\mathbf{m} / \mathbf{s})\end{array}$ & $\begin{array}{c}\text { Rated Wind } \\
\text { speed (m/s) }\end{array}$ & $\begin{array}{c}\text { Cut-out wind } \\
\text { speed (m/s) }\end{array}$ \\
\hline N90/2300 & 2300 & 90 & 80 & 4 & 13 & 25 \\
s77/1500 & 1500 & 77 & 61.5 & 4 & 15 & 20 \\
N27/150 & 150 & 27 & 30 & 4 & 14 & 25 \\
\hline
\end{tabular}

Table 4.

Yearly Power Production of Nordex Wind Turbine

\begin{tabular}{|cccc|}
\hline Turbine & $\begin{array}{c}\text { Active Power } \\
(\mathbf{k W})\end{array}$ & $\begin{array}{c}\text { Energy produced } \\
(\mathbf{M W h})\end{array}$ & Capacity Factor \\
\hline N90/2300 & 831 & 7218 & 0.36 \\
S77/1500 & 560 & 4860 & 0.37 \\
N27/150 & 71 & 618 & 0.47 \\
\hline
\end{tabular}

Turbine costs are assessed, utilizing the thumb rule of US $\$ 1000 \mathrm{kWh}$, like $\$ 450,000$. The whole mechanism costs are taken $20 \%$ of turbine rate and procedure and preservation as $2 \%$ of the turbine charges every year. With the life of two decades and a genuine interest rate of $5 \%$ for a turbine, the rate of electrical energy is ascertained as 3.6 pennies for each $\mathrm{kWh}$ at advanced costs. This comprehensive analysis of economic benefits and size recommends that an off- 
Citation: Kaloi,G.S., Wang, J., Baloch,M.H. and Tahir, S. (2017) Wind Energy Potential at Badin and Pasni Costal Line Pakistan.. International Journal of Renewable Energy Development, 6(2), 103-110,https://doi.org/10.14710/ijred.6.2.103-110

$\mathrm{P}$ a g e | 110

grid wind power approach for neighborhood groups is liable to be conceived critically.

The matter of fact to be taken into consideration is that the needs of the people and industry for energy are met by the turbines all over the year, but the considerable variability in power production in the day and over the season give rise to the need of a backup system for energy storage that might be in the form of diesel generator or battery or grid connection in case of a stand-alone system, which will increase its cost extensively. It is to be taken into consideration that the estimated price that is calculated by various parameters is feasible according to the international standards but might be a number of people residing in the rural areas remain unable to afford its cost, therefore it is vital.

Turbines for commercial purposes are designed most frequently for the sites with high-speed winds and don't execute much efficiently in low-speed winds. Several turbines are designed to take benefit of the local wind system that consequently diminishes the cost. Mechanizing the turbines on the local level will bring down the bills profoundly.

\section{Conclusion}

As an energy-starved and progressive country, new resources of affordable and clean energy are the need of the hour for Pakistan. Currently, by providing the minimal amount of electrical energy to almost half of the poor households. a huge advancement in the quality of life can be brought. Due to the low effect on environment, suitable cost, and sustainability of wind power generation is becoming a viable option. By categorizing the class 4, Badin and Pasni in Pakistan are the most appropriate wind power sites for small, stand-alone and larger wind power projects. Though the people in rural communities and far away areas can never be able to afford the price of electricity, even if it exists according to the international standards. The designing and working mechanism of these turbines should be suitable according to local conditions of the region.

\section{Acknowledgments}

Support of Natural Science Foundation P R China under Grant No. 61374155, and the Specialized Research Fund for the Doctoral Program of Higher Education, PR China under Grant No. 20130073110030 is highly acknowledged.

\section{References}

Alam, A. (2013). Electric power consumption, foreign direct investment and economic growth: A comparative study of India and Pakistan. World Journal of Science, Technology and Sustainable Development 10(1), 55-65.

Baloch, M. H., G. S. Kaloi and Z. A. Memon (2016). Current scenario of the wind energy in Pakistan challenges and future perspectives: A case study. Energy Reports 2, 201210 .
Bhutto, A. W. and S. Karim (2007). Energy-poverty alleviation in Pakistan through use of indigenous energy resources.Energy for sustainable development 11(1), 5867.

Blackman, A. and X. Wu (1999). Foreign direct investment in China's power sector: trends, benefits and barriers. Energy policy 27(12), 695-711.

Boyd, D. T. (2003). Oklahoma oil, natural gas, and our place in the big picture. Oklahoma Geology Notes 63(1), 4-30.

Fettweis, G. and E. Zimmermann (2008). ICT energy consumption-trends and challenges. Proceedings of the 11th International Symposium on Wireless Personal Multimedia Communications.

Goswami, D. Y. and F. Kreith (2015). Energy Efficiency and Renewable Energy Handbook, CRC Press.

Hasan, S. A., M. I. Subhani and A. Osman (2012). The energy short fall and its after effects (a case study for Karachi city in context to Karachi electric supply corporation). Science Series Data Report 4(2), 42-49.

Kaloi, G. S., J. Wang and M. H. Baloch (2016) Dynamic modelling and Control of DFIG for Wind Energy Conversion System Using Feedback Linearization. J Electr Eng Technol.; 11(5), 1137-1146

Kaloi, G. S., J. Wang and M. H. Baloch (2016). Active and reactive power control of the doubly fed induction generator based on wind energy conversion system. Energy Reports 2, 194-200.

Kaloii, G.S. , J. Wang and M. H. Baloch (2016). Study of stabilty analysis of a grid connected Doubly fed induction generator based on wind energy Application. Indonesian Journal of Electrical Engineering and Computer Science $3(2)$.

Menges, R. and W. Pfaffenberger (2015). Promotion of Renewable Energy Sources in the European Union. International Journal of Renewable Energy Development 4(3), 171.

Mirza, U. K., N. Ahmad, K. Harijan and T. Majeed (2009). Identifying and addressing barriers to renewable energy development in Pakistan. Renewable and Sustainable Energy Reviews 13(4), 927-931.

Mohammadi, M., A. Mohammadi and S. Farahat (2016). A New Method for Horizontal Axis Wind Turbine (HAWT) Blade Optimization. International Journal of Renewable Energy Development 5(1), 1-8.

Pakistan, B. M. (2013). Bank Mohtasib Pakistan Annual Report 2013

Patel, M. R. (2005). Wind and solar power systems: design, analysis, and operation, CRC press.

Sahir, M. H. and A. H. Qureshi (2008). Assessment of new and renewable energy resources potential and identification of barriers to their significant utilization in Pakistan. Renewable and Sustainable Energy Reviews 12(1), 290298.

Sheikh, M. A. (2010). Energy and renewable energy scenario of Pakistan. Renewable and Sustainable Energy Reviews 14(1), 354-363.

Siddique, S. and R. Wazir (2016). A review of the wind power developments in Pakistan. Renewable and Sustainable Energy Reviews 57, 351-361. 